\title{
MONITORAMENTO DOS AGROTÓXICOS QUINCLORAC E CARBOFURAN NO RIO CAMBORIÚ, MUNICÍPIO DE CAMBORIU, SANTA CATARINA
}

\author{
Vanessa Andreatta Matias ${ }^{1}$ e Márcio da Silva Tamanaha ${ }^{2}$
}

\begin{abstract}
Resumo: No Brasil, um dos maiores produtores de arroz irrigado é o estado de Santa Catarina, onde se localiza a bacia hidrográfica do rio Camboriú. A utilização de agroquímicos na rizicultura confere a esta prática um grande potencial de poluição hídrica, podendo-se destacar os agrotóxicos quinclorac e carbofuran, os quais são utilizados em larga escala nesse cultivo. Durante doze meses (maio de 2014 a abril de 2015) quatro pontos da bacia foram visitados e 48 amostras de água foram coletadas (1 coleta/ponto/mês). Estas amostras foram preparadas por extração em fase sólida e analisadas em cromatógrafo líquido acoplado a espectrômetro de massa em tandem. Os resultados mostraram que o quinclorac foi encontrado apenas nas amostras coletadas em pontos próximos a locais de cultivo do arroz, já o carbofuran foi encontrado em outros pontos também. Todas as amostras contaminadas foram coletadas durante o período de safra. Além disso, o quinclorac esteve presente em valores detectáveis e em valores quantificáveis em um número menor de amostras do que o agrotóxico carbofuran. Contudo, o carbofuran não esteve presente em concentrações maiores do que os valores máximos permitidos sugeridos pela EMBRAPA e pelo Ministério da Saúde. Para o quinclorac não há valores limites recomendados.
\end{abstract}

Palavras-chave: Arroz irrigado. Espectrometria de massas. Resíduos. Água de superfície.

\section{Introdução}

O arroz irrigado, (Oryza sativa L), gramínea do gênero Oryza, está entre as principais culturas que compõe a alimentação da população mundial. Sua cepa selvagem é originária do sul da China de onde, no século VII, foi levado à Europa, de lá trazido ao Brasil em meados do século XVI (CADORIN, 2011), e atualmente está em todos os continentes (SOUZA, 2012). Hoje o Brasil ocupa o $8^{\circ}$ lugar no ranking de produção mundial, o que representa $1,8 \%$ da produção total (EPAGRI/CEPA, 2013). Em 2015 o país obteve uma safra de 12.470 .280 toneladas de arroz em casca, a qual foi $2,6 \%$ maior do que a safra de 2014, com área de produção 1,8\% menor (IBGE, 2015). No Brasil, os dois principais estados produtores de arroz em área plantada são os estados do Rio Grande do Sul (RS) e Santa Catarina (SC) (EPAGRI/CEPA, 2013). Em Santa Catarina entre as safras de 2013/14 e $2014 / 15$, houve um aumento de $3,19 \%$ no rendimento médio, cultivados em 148.970 hectares.

No estado de Santa Catarina, basicamente todo o cultivo de arroz irrigado é feito no sistema de pré-germinação. Este sistema caracteriza-se pela semeadura de sementes pré-germinadas em solos previamente inundados (CADORIN, 2011). Apesar disso, as condições de clima e solo da região do baixo vale do Itajaí (SC), não permitem altos rendimentos de grão em um único cultivo, mas permitem que se faça o cultivo do rebrote, ou cultivo da soca do arroz, e com isso, os produtores podem alcançar rendimentos de 10 a 12 t/ha em uma única safra (EPAGRI, 2015). A cidade de Camboriú, localizada no baixo vale do Itajaí, tem 1.200 hectares utilizados para a produção de arroz irrigado e produz em média 10.400 toneladas do grão em casca com o emprego da rizicultura irrigada no sistema de pré-germinação (IBGE, 2016). Hoje, dentre as principais atividades econômicas da cidade estão o extrativismo de granito e a agricultura, onde se destaca a rizicultura (CAMBORIÚ, 2015).

A cidade de Camboriú bem como a cidade de Balneário Camboriú está inserida na bacia hidrográfica do rio Camboriú, a qual se localiza no litoral norte de Santa Catarina, e drena pouco mais de $199 \mathrm{~km}^{2}$ (Figura 1). Dentre os principais rios que compõem esta

\footnotetext{
트-mail: vmatias@univali.br

2E-mail: mt@univali.br

Universidade do Vale do Itajaí (UNIVALI). Centro de Ciências Tecnológicas da Terra e do Mar, Setor E2 - sala 106 - Rua Uruguai, 458, Centro Itajai, SC
} 
REA - Revista de estudos ambientais (Online)

v.18, n. 1, p.30-45, jan./jun. 2016

bacia estão o ribeirão dos Macacos, rio do Salto, rio do Braço, rio Pequeno e o seu rio principal, o rio Camboriú. A uma altitude de $735 \mathrm{~m}$ acima do nível do mar, o Morro do Gavião, na localidade de Limeira (interior da cidade de Camboriú) é o ponto mais alto da bacia, e é lá que estão suas principais nascentes (COMITÊ CAMBORIÚ, 2015).

$\mathrm{Na}$ produção do arroz do irrigado as principais pragas animais para as quais os agrotóxicos são utilizados são: Spodoptera frugiperda (lagarta-da-folha), Oryzophagus oryzae (gorgulho-aquático, chamado também de bicheira-da-raiz, quando em estágio larval), Tibraca limbativentris (percevejo-docolmo) e Oebalus poecilus (percevejo-dogrão) (EMBRAPA, 2015). Já as espécies vegetais que mais acometem as plantações de arroz irrigado são Echinodorus spp (chapéu de couro), Eleusine sp (capim pé de galinha) e o Echinochoa spp (capim arroz). (EMBRAPA, 2015).

A rizicultura irrigada demanda um grande volume de água, sendo necessários aproximadamente 2.000 litros de água para cada quilo do grão produzido (BIANCHIN et al., 2015), além disso, este cultivo demanda um elevado número de insumos agrícolas, com destaque para os agrotóxicos (herbicidas, inseticidas e fungicidas), os quais podem ser utilizados de forma combinada (SILVA, 2011). Por isso, dentre os cultivos agrícolas do sul do Brasil, o cultivo do arroz irrigado tem sido apontado com alto potencial contaminante dos mananciais hídricos (SILVA, 2009).

Herbicidas com diferentes ingredientes ativos são utilizados no controle de monocotiledôneas e dicotiledôneas e podem ser empregados antes ou depois do aparecimento das plantas alvo. Dentre esses ingredientes ativos se pode citar alguns com alto consumo, como Metsulfuron, 2,4-D Amina, Propanil, Bentazon, quinclorac, Clomazone, Ethoxysulfuron, Bispyribacsodium, Glifosato, Molinate, Pyrazosulfuron e o Fenoxaprop-p-ethyl. Além destes ingredientes ativos, se pode citar outros com funções inseticidas e que também possuem um alto consumo, como o Fipronil, Carbaril, Fenitrotion (WILLEMAN et al., 2007) e carbofuran (KRUZ, 2007). O inseticida carbofuran e o herbicida quinclorac, em diversos trabalhos, se apresentaram na maioria das amostras coletadas, como no trabalho de Grützmacher (2008), onde estes agrotóxicos estiveram presentes no maior número de amostras coletadas durante o período de safra analisada.
O quinclorac (3,7-dicloroquinolina-8ácido carboxílico) é um composto químico mimetizador de auxina, o que o leva a apresentar baixa toxicidade aos animais (EPAGRI/ CEPA, 2013). Ele é enquadrado como herbicida dentro dos ALS (Aceto Lactato Sintase) - herbicidas inibidores da enzima aceto lactato sintase (RIZZARDI et al., 2002). Segundo a classificação toxicológica da ANVISA, o quinclorac é um agrotóxico moderadamente tóxico, enquadrado como Classe III e deve ser utilizado somente pós-emergência com possibilidade de reuso dentro de um intervalo de 90 dias (CONCENÇO, 2008). Ele apresenta uma solubilidade em água de 62 mg.L-1 e uma coeficiente de partição octanolágua (Kow) de 0,770795 (SILVA, 2011).

A Echinochloa spp. é uma das pragas que mais causam problemas para 0 cultivo do arroz irrigado, pois possui crescimento acelerado e agressivo, além de se parecer muito com a espécie cultivada e sua principal forma de controle se dá pela utilização do quinclorac (PRIMEL, 2005). Contudo, esta espécie de planta daninha, desde o final da década de 90 , apresenta resistência ao agrotóxico quinclorac (CONCENÇO, 2008).

O carbofuran é classificado como inseticida/nematicida carbamato sistêmico. No meio ambiente é metabolizado por hidroxilação a 3-hidroxi-carbofuran e este a 3-ceto-carbofuran (TREVISAN, 2002). Este derivado do carbamato apresenta 0 mecanismo de ação baseado na inibição da acetilcolinesterase - permitindo assim a ação mais intensa e prolongada do mediador químico nas sinapses colinérgicas, em nível de membrana pós-sináptica - e são os responsáveis pelo maior número de intoxicações humanas no meio rural (CALDAS, 2009). Ele é o principal principio ativo de uma série de agrotóxicos amplamente utilizados em todo o mundo na indústria, agricultura e uso doméstico. Possui ponto de fusão alto e pressão de vapor baixa e seu tempo de meia vida é dependente do $\mathrm{pH}$ do meio, já que a taxa de hidrólise aumenta juntamente com $\circ \mathrm{pH}$ (SILVA, 2009). A ANVISA classifica o carbofuran como sendo de Classe I, ou seja, extremamente tóxico (ANVISA, 2015). No cultivo do arroz irrigado este composto químico deve ser aplicado após a inundação e/ou do aparecimento das pragas, tendo um intervalo mínimo de replicação de 30 dias. No geral, sugere-se que seja utilizado de 0,25 a $0,40 \mathrm{~kg} / \mathrm{ha}$ de ingrediente ativo (FMC, 


\section{REA - Revista de estudos ambientais (Online) v.18, n. 1, p.30-45, jan./jun. 2016}

2015). Sua solubilidade em água é de 62 mg. $\mathrm{L}^{-1}$ e seu coeficiente de partição octanolágua (Kow) é de 30,90295 (SILVA, 2009).

No Brasil a legislação vigente contempla apenas o valor máximo permitido (VMP) de um dos agrotóxicos analisados, o carbofuran. $O$ qual é permitido pelo Ministério da Saúde em água potável na concentração máxima de $7 \mathrm{ppb}$ (CALDAS et al., 2011). A EMBRAPA sugere para o mesmo agrotóxico um valor máximo permitido em água de rio de 4 ppb (AGEITEC, 2015), enquanto a Organização Mundial de Saúde (OMS) sugere uma concentração de 0,7 ppb (REIMCHE, 2010). O agrotóxico quinclorac não é citado ou regulamentado nenhuma vez pelo Ministério da Saúde, Empresa Brasileira de Pesquisa Agropecuária (EMBRAPA) ou OMS. A European Economic Community (EEC) permite para água potável valores máximos individuais de agrotóxicos de 0,01 ppb e para a soma de todos os agrotóxicos presentes um VMP de 0,05 ppb (CALDAS et al., 2011).

Mesmo chegando em pequenas quantidades aos rios e lagos, os agrotóxicos podem causar prejuízos ao meio ambiente, já que sofrem bioacumulação e possuem grande persistência, sendo prejudiciais ao longo da cadeia alimentar, algumas vezes apresentando-se cancerígenos e mutagênicos (FARIA, 2004). Eles podem atingir as águas por drenagem, escoamento superficial e subsuperficial, erosão, volatilização, entre outros (SILVA, 2009).
Além disso, os agrotóxicos podem ser adsorvidos pelas argilas contidas no solo e permanecem expostos às inúmeras reações químicas, físicas e biológicas (COSTA; SANT'ANA, 2008), afetando assim a saúde pública e o meio ambiente (COSTA, 2007).

Desta forma, o objetivo deste trabalho foi avaliar a presença dos agrotóxicos quinclorac e carbofuran em água superficial de rios de áreas adjacentes à rizicultura da bacia do rio Camboriú, empregando a extração em fase sólida (SPE) e a cromatografia líquida acoplada à espectrometria de massa tandem (LC/MS/MS), além de analisar e comparar os resultados obtidos com a legislação vigente.

\section{Metodologia}

\section{1 Área de estudo e coleta}

Para as amostragens foram selecionados quatro pontos de coletas, cada um localizado em um rio principal da bacia hidrográfica do rio Camboriú, todos na cidade de Camboriú. Os pontos foram escolhidos de forma que a bacia toda fosse representada durante a pesquisa, com enfoque principal para as áreas alteradas pela agricultura, as quais se localizam na cidade de Camboriú. As coordenadas geográficas dos pontos de coleta estão descritas na tabela 1.

Tabela 1 - Coordenadas geográficas dos pontos de coleta selecionados, relacionados com suas respectivas localidades

\begin{tabular}{ccccc}
\hline Pontos & Bairro & Rio & Latitude & Longitude \\
\hline $\mathbf{1}$ & Cerro & do Braço & $27^{\circ} 03^{\prime} 30.1^{\prime \prime} \mathrm{S}$ & $48^{\circ} 42^{\prime} 15.5^{\prime \prime} \mathrm{W}$ \\
$\mathbf{2}$ & Morretes & Canoas & $27^{\circ} 03^{\prime} 18.1^{\prime \prime} \underline{\mathrm{S}}$ & $48^{\circ} 40^{\prime} 55,1^{\prime \prime} \mathrm{W}$ \\
$\mathbf{3}$ & Centro & Camboriú & $27^{\circ} 01^{\prime} 16.6^{\prime \prime} \underline{\mathrm{S}}$ & $48^{\circ} 39^{\prime} 25.8^{\prime \prime} \mathrm{W}$ \\
$\mathbf{4}$ & Rio Pequeno & Pequeno & $27^{\circ} 01^{\prime 2} 27.9^{\prime \prime} \mathrm{S}$ & $48^{\circ} 38^{\prime} 31.1^{\prime \prime} \mathrm{W}$ \\
\hline
\end{tabular}

O P1 (ponto de coleta 1), localizado no Bairro Morretes, é banhado pelo rio do Braço. Em todo seu entorno há o cultivo do arroz irrigado que tem sua captação e sua saída de água direta para o rio, acima deste ponto há também inúmeras plantações de arroz irrigado, e toda água utilizada nesses cultivos passa pelo P1. Seguindo o curso do rio, aproximadamente a 150 metros, há uma pequena represa, a qual é monitorada e administrada pelos agricultores da região. Em seu entorno há apenas uma moradia (aproximadamente $400 \mathrm{~m}$ de distância). Durante todo o período de amostragem houve uma variação na altura da coluna d'água, entre $1,7 \mathrm{~m}$ nos meses de cheia $\mathrm{e}$ $0,3 \mathrm{~m}$ nos meses de seca.

As coletas feitas no P2, Bairro Cerro, representam as águas do rio dos Macacos. Este ponto, apesar de ser margeado por 
REA - Revista de estudos ambientais (Online) v.18, n. 1, p.30-45, jan./jun. 2016

pequenas pastagens e ter duas casas próximas (150 metros de distância aproximadamente), tem a influência direta da rizicultura, já que existem muitos quadros de arroz irrigado nas proximidades, os quais utilizam as águas do rio de forma direta devolvendo-as a ele. Acima deste ponto há muitas plantações de arroz irrigado, e toda água utilizada nestes cultivos passam pelo P2. No período de amostragem a coluna d'água variou entre $1,3 \mathrm{~m}$ nas estações de seca a 2,5 m durante as estações de cheia.

Já as coletas realizadas no $P 3$, foram feitas no rio Camboriú, bairro Centro, próximo à estação de coleta de água da empresa SESB (Secretaria de Saneamento
Básico), que abastece a cidade de Camboriú. Neste ponto do rio não há o cultivo de arroz próximo, contudo, é um trecho que recebe água dos pontos 1 e 2 , tendo diversas moradias próximas e pouca mata ciliar. Neste ponto a altura da coluna d'água variou entre 1,6 e $3 \mathrm{~m}$.

Também foram feitas coletas no P4, localizado no bairro io Pequeno, de rio com mesmo nome. No P4 há muitas habitações no entorno, nenhum cultivo na margem (apenas a alguns quilômetros de distância) e são visíveis as saídas de esgoto no local. Neste ponto, a altura da coluna d'água variou entre 1,5 a 2,4m, aproximadamente.

Figura 1 - Mapa da área da bacia do Rio Camboriú com destaque para os pontos de coletas

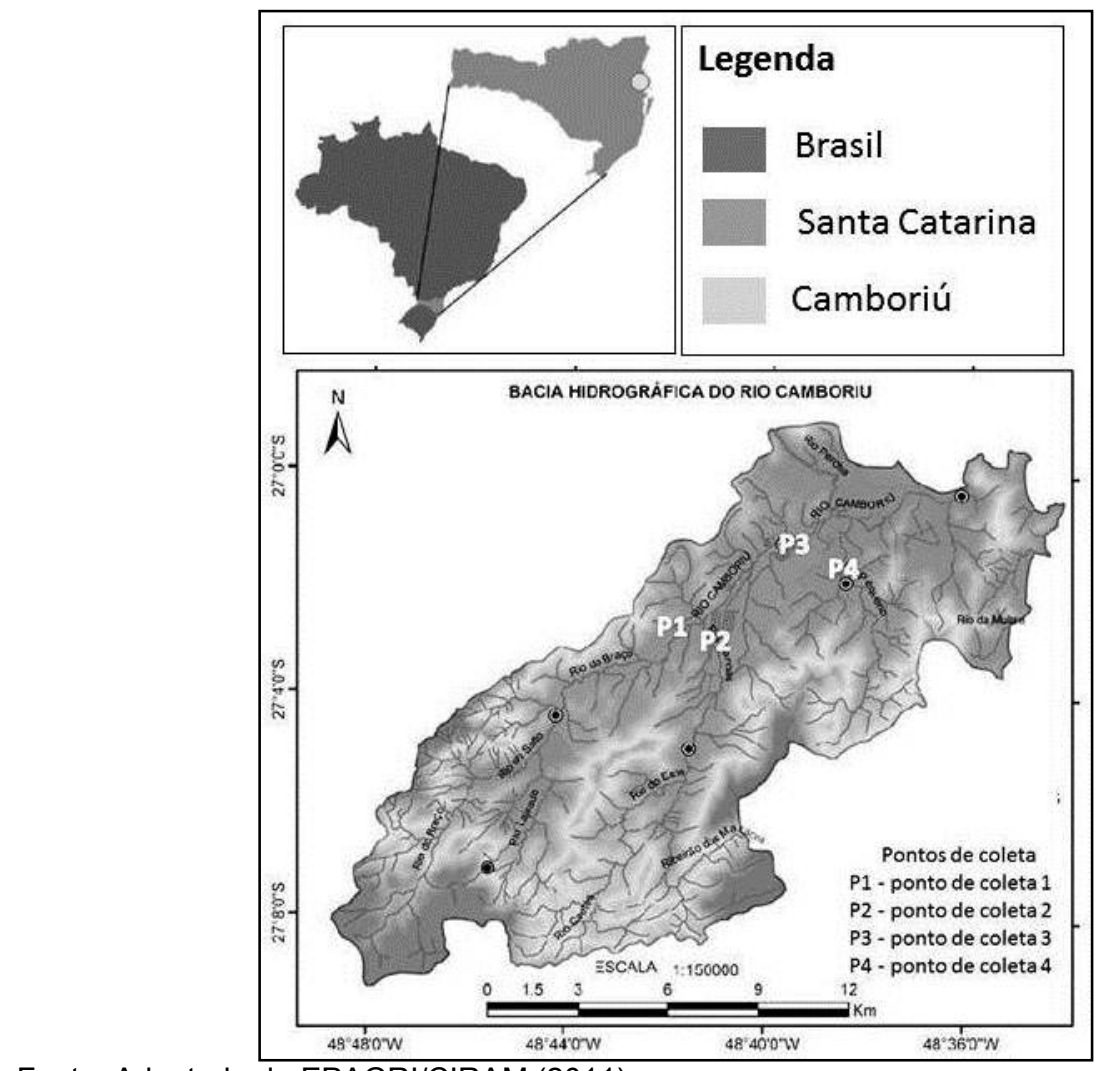

Fonte: Adaptado de EPAGRI/CIRAM (2011)

Durante o monitoramento foram feitas 12 coletas nos quatro pontos (P1, P2, $\mathrm{P} 3$ e P4) com intervalo de um mês entre uma e outra, abrangendo a safra completa e o período de entressafra, totalizando de 48 amostras durante todo o período de estudo. Em cada ponto foi coletado aproximadamente 2 litros de água com auxílio de uma garrafa adaptada com furos de $1 \mathrm{~cm}^{2}$ espaçados a uma distância de aproximadamente cinco centímetros entre um e outro (na metade de cima). No fundo da garrafa foi acoplado um peso de aproximadamente dez quilogramas para que a garrafa submergisse com facilidade e em sua tampa foi acoplada uma alça onde era amarrada uma corda para emersão. Desta forma, a garrafa era inundada lentamente com a água do rio enquanto descia pela coluna d'agua, abrangendo todo o corpo d'água (Figura 2). 


\section{REA - Revista de estudos ambientais (Online) v.18, n. 1, p.30-45, jan./jun. 2016}

A garrafa utilizada possui um volume total de 5 litros e assim que retirada do rio era levada imediatamente para um balde onde a amostra era despejada, homogeneizada e dessa amostra um volume de dois litros era transferido para uma garrafa devidamente identificada e limpa. Esta garrafa ficava armazenada em uma caixa térmica refrigerada durante 0 deslocamento para o laboratório.

Figura 2 - Garrafa de coleta de amostra bruta

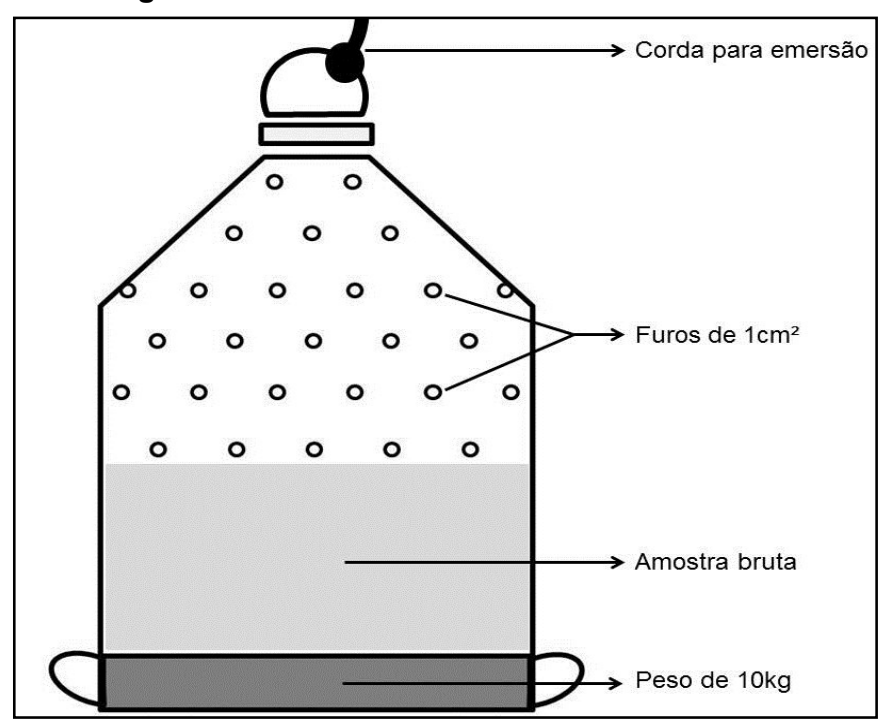

Fonte: Autores (2016)

\subsection{Extração}

Neste estudo foram utilizados 2 agrotóxicos com elevados padrões de pureza - quinclorac e carbofuran, ambos da empresa Sigma-Aldrich ${ }^{\circledR}$. Para cada pesticida testado foi feita uma solução estoque de $0,01 \mathrm{mg} \cdot \mathrm{L}^{-1}$, preparadas em metanol para $\mathrm{HPLC}$ e armazenadas a $-18^{\circ} \mathrm{C}$. A partir destas soluções foram preparadas, também com metanol, soluções contendo 10 $\mathrm{mg} . \mathrm{L}^{-1}$ para cada agrotóxico, as quais foram utilizadas para o feitio da curva de calibração e para a fortificação (DEMOLINER et al., 2010).

Os cartuchos de SPE utilizados tinham a fase C18 $200 \mathrm{mg} / 3 \mathrm{ml}$ da marca

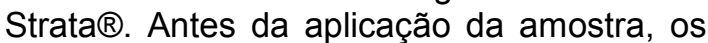
cartuchos foram condicionados passando-se consecutivamente $3 \mathrm{ml}$ de metanol para HPLC, seguidos de $3 \mathrm{ml}$ de água purificada e $3 \mathrm{ml}$ de água purificada acidificada $(\mathrm{pH} \mathrm{3,0)}$ com uma solução de ácido fosfórico $1 \mathrm{M}$. Após o preparo dos cartuchos, as amostras foram acidificadas $(\mathrm{pH} \mathrm{3,0)}$ por adição de uma solução de ácido fosfórico $1 \mathrm{M}$, homogeneizadas e aplicadas nos cartuchos para percolação em $10 \mathrm{ml} / \mathrm{mim}$ auxiliada por uma bomba de vácuo. Ao término desta etapa, foram eluidos $1 \mathrm{~mL}(500 \mu \mathrm{L}+500 \mu \mathrm{L})$ de metanol para HPLC, o qual gerou uma amostra final com o volume de $1 \mathrm{~mL}$. Este procedimento foi utilizado em todas as extrações realizadas. Os produtos deste processo foram levados ao LC-MS/MS com um volume de injeção de $20 \mu \mathrm{L}$ (DEMOLINER et al., 2010).

\subsection{Curva de calibração}

Para determinar a curva de calibração, 6 concentrações diferentes foram analisadas, todas em triplicata, sendo elas: $1 ; \quad 9,5 ; \quad 16,5 ; \quad 23,5 ; \quad 37,5$ e $50 \quad \mu g \cdot \mathrm{L}^{-1}$. Inicialmente, 6 volumes de $1,5 \mathrm{~L}$ de água purificada foram acidificados a $\mathrm{pH} \mathrm{3,0}$ com uma solução de ácido fosfórico $1 \mathrm{M}$. Posteriormente, cada volume recebeu uma concentração diferente de agrotóxicos e então estas alíquotas foram divididas em 3 partes de $500 \mathrm{ml}$ cada. Estas partes, já acidificadas e fortificadas foram extraídas em cartucho devidamente ativado e o seu produto foi levado ao LC-MS-MS.

\subsection{Amostras}

Inicialmente, as amostras vindas do campo foram homogeneizadas e filtradas com o filtro GF-4 de $47 \mathrm{~mm}$, da empresa 


\section{REA - Revista de estudos ambientais (Online) v.18, n. 1, p.30-45, jan./jun. 2016}

Macherey-Nagel $\circledast$ para remoção das partículas em suspensão. Após a filtração foram separadas duas alíquotas de $500 \mathrm{ml}$ cada, as quais foram acidificadas, extraídas com auxílio dos cartuchos e levadas ao LCMS-MS.

\subsection{Fortificação}

Para a fortificação foi utilizada água coletada em uma nascente da bacia hidrográfica do rio Camboriú, nascente que dá origem ao rio dos Macacos e que não corria o risco de estar contaminada, já que não há próximo, ou antes dela, nenhum tipo de cultivo. O ponto de coleta na nascente localiza-se no bairro Vila Conceição $\left(27^{\circ} 12^{\prime} 279,9^{\prime \prime} S, \quad 48^{\circ} 70^{\prime} 00,87 \mathrm{~W}\right)$, ele foi visitado seis vezes e em cada visita dois litros de água foram coletados e tratados até a filtração em filtro GF-4, da mesma maneira que as amostras brutas.

Depois disso, as amostras foram divididas em alíquotas de $500 \mathrm{ml}$, as quais foram acidificadas com solução de ácido fosfórico $1 \mathrm{M}$ e fortificadas em diferentes concentrações para então serem percoladas no cartucho de SPE e levadas ao LC-MSMS. Isto foi realizado para que se pudesse conhecer o comportamento dos agrotóxicos analisados na água dos rios.

\subsection{Análise cromatográfica}

As amostras - resultadas do SPE foram analisadas em um cromatógrafo liquido Agilent Technologies 1200 Series, equipado com uma bomba quaternária, um injetor automático e um compartimento de colunas termostatizado, utilizando para a separação cromatográfica uma coluna XTerra®MS C18. A fase móvel foi composta por água purificada + ácido fórmico1\% e metanol para HPLC puro, em uma proporção de $30: 70(\mathrm{v} / \mathrm{v})$ respectivamente. A corrida foi realizada no modo isocrático a uma taxa de fluxo de $250 \mathrm{ml} / \mathrm{min}^{-1}$, o que resultou num tempo de corrida de 5 minutos. A temperatura do compartimento da coluna foi ajustada para permanecer em $20^{\circ} \mathrm{C}$, e a injeção foi feita no cromatógrafo com o produto da preparação com SPE, em um volume de $20 \mu \mathrm{L}$ (DEMOLINER et al., 2010).

Apesar de a cromatografia líquida (LC) ser inúmeras vezes escolhida para o processo de análise por proporcionar separações muito eficientes e de alta resolução (HARRIS, 2012), ela sozinha, não é capaz de identificar as moléculas selecionadas. Para isto, o LC foi acoplado a um detector Applied Biosystems $®$, o qual é empregado conforme suas propriedades e natureza das amostras. Esta união propicia alta seletividade e eficiência de separação com a obtenção de informação estrutural da massa molar e aumento adicional da seletividade e detectabilidade (CHIARADIA, 2009).

\subsection{Espectrometria de massa}

A detecção dos agrotóxicos foi realizada através do detector espectrômetro de massas modelo 3200 Q TRAP LC/MS/MS System (Applied Biosystems $\AA$ ), acoplado ao aparelho de cromatografia líquida. $O$ fluxo de gás nebulizador foi ajustado para $50 \mathrm{~L} . \mathrm{h}^{-1} \mathrm{e}$ o do gás de solvatação para 350-550 L.h ${ }^{-1}$. Para a operação no modo MS-MS, o gás de colisão utilizado foi o nitrogênio, com uma pressão de $3,5.10^{-3} \mathrm{mbar}$.

Para a otimização das condições da espectrometria de massa por detecção tandem (MS/MS), foram realizadas injeções das soluções padrões individuais em modos de ionização negativo e positivo, varredura completa e produto íon com espectro de massa com diferentes valores de cone e energias de colisão. Isto foi feito para que a escolha do modo de ionização, identificação dos íons percursores/mãe e produtos, seleção do cone colisão e tensões tivessem as condições mais favoráveis para a análise do analitos alvo.

Após a otimização da energia de célula de colisão do triplo quadrupolo, os íons foram monitorados sob o método de reações múltiplas em tempo programado (MRM). No modo de operação de monitoramento de reações múltiplas (MRM, do inglês Multiple Reaction Monitoring) o espectrômetro foi programado de forma que dois ou mais íons fossem novamente fragmentados (CALDAS, 2009). Neste modo, duas transições dos íons precursores são selecionadas para cada pesticida, uma para quantificação e outra para qualificação.

\section{Resultados}

As curvas de calibração calculadas para cada agrotóxico foram expressas por equações da reta e coeficientes de determinação $\quad\left(R^{2}\right) \quad($ Tabela 2$)$. Os 


\section{REA - Revista de estudos ambientais (Online) v.18, n. 1, p.30-45, jan./jun. 2016}

coeficientes de determinação ficaram sempre em valores acima de 0,99 , o que gerou uma confiabilidade dos resultados muito próxima a $100 \%$, desta forma a linearidade do método foi comprovada (RIBANI et al., 2004). O uso dos padrões permitiu determinar a faixa de aplicação do método, onde o intervalo entre os valores superior e inferior das substâncias em análise atendem aos requisitos de precisão e exatidão
(RIBANI et al., 2004). Desta forma foi calculado o limite de quantificação (LOQ) baseado na amplitude do pico do padrão com a proporção de 10 vezes a amplitude do ruído e o limite de detecção (LOD) que foi baseado na amplitude do pico do padrão com proporção de 5 vezes a amplitude do ruído. Os valores de LOD e LOQ estão representados na Tabela 3 .

Tabela 2 - Equações da reta e valores de coeficiente de determinação $\left(R^{2}\right)$ para cada agrotóxico testado

\begin{tabular}{ccc}
\hline Composto & Equação da reta & $\mathbf{R}^{2}$ \\
\hline Carbofuran & $y=2 E+06 x-5194,7$ & 0,9973 \\
Quinclorac & $y=184148 \times 15,547$ & 0,9969 \\
\hline
\end{tabular}

Fonte: Autores (2016)

Tabela 3 - Limites de detecção (LOD) e limites de quantificação (LOQ) para os agrotóxicos analisados por LC-MS-MS, da bacia hidrográfica do rio Camboriú

\begin{tabular}{ccc}
\hline Composto & Limite de detecção (LOD) & Limite de quantificação (LOQ) \\
\hline Carbofuran & $0,0002 \mathrm{ppb}$ & $0,0009 \mathrm{ppb}$ \\
Quinclorac & $0,0004 \mathrm{ppb}$ & $0,0029 \mathrm{ppb}$ \\
\hline
\end{tabular}

Fonte: Autores (2016)

Presente na água coletada nas nascentes, bem como nas amostras dos pontos de coleta, há substâncias interferentes não encontradas na água empregada para realizar as diluições utilizadas na curva de calibração. Estas substâncias interferem no grau de ionização das moléculas causando problemas de retenção secundária, o que é responsável por picos com caudas, assim o tempo médio de retenção dos analitos alvo é aumentado (RUELA et al., 2009) como mostra a Figura 3.

$\mathrm{Na}$ espectrometria de massa tandem (MS-MS) é feito o acoplamento de dois ou mais analisadores de massa em conjunto (SKOOG et al., 2006). Assim, os analisadores de massa separaram os íons de mesma razão $\mathrm{m} / \mathrm{z}$ e estabeleceram uma relação entre o íon de interesse isolado e outros íons que foram gerados a partir da sua decomposição induzida (PEREIRA, 2012). Pela análise espectrométrica, neste trabalho, foi constatado o tamanho das massas e das fragmentações das moléculas dos agrotóxicos testados. Os valores em
Dalton (Da) estão representados na Tabela 4.

Dentre as 48 amostras analisadas em duplicata 6 delas apresentaram valores detectáveis (LOD) e 8 apresentaram valores quantificáveis (LOQ) para o agrotóxico carbofuran. Já para o herbicida quinclorac, 2 amostras apresentaram valores detectáveis e uma amostra apresentou valor quantificável (Tabela 5). Todas as amostras que apresentaram valores detectáveis e quantificáveis foram coletadas no período de cultivo do arroz irrigado, que se iniciou em setembro de 2014 e terminou em abril de 2015 , período que representou $66,66 \%$ do número total de amostras coletadas.

Estas constatações foram, em parte, compatíveis às obtidas por Silva (2009) em um estudo realizado em três municípios do sul do Brasil, onde carbofuran e quinclorac estiveram presentes em $38 \%$ e $33 \%$ das amostras coletadas durante o período de cultivo, respectivamente. Grützmacher et al. (2008) em seu trabalho realizado na região sul do Rio Grande do Sul, também obteve resultados semelhantes, onde carbofuran e 


\section{REA - Revista de estudos ambientais (Online)} v.18, n. 1, p.30-45, jan./jun. 2016

quinclorac estiveram presentes em 35 e $33 \%$ das amostras analisadas. Contudo, em um estudo realizado no rio Vacacaí-Mirim (Santa Maria - RS), nas safras de 2004 e 2008 , o agrotóxico carbofuran esteve presente na maioria das amostras (quase $90 \%$ delas) (MARCHESAN, 2010). No presente estudo, assim como nos demais trabalhos citados, o percentual de amostras que apresentaram o agrotóxico carbofuran, dentro das amostras que exibiram valores de LOQ ou LOD, foi maior do que o percentual de amostras que apresentaram o agrotóxico quinclorac.

Figura 3 - Cromatograma de uma alíquota de água coletada na nascente e fortificada a 1 $\mu \mathrm{g} \cdot \mathrm{L}^{-1}$, com destaque para os picos gerados a partir das massas do carbofuran (A e B) e do quinclorac (C e D).

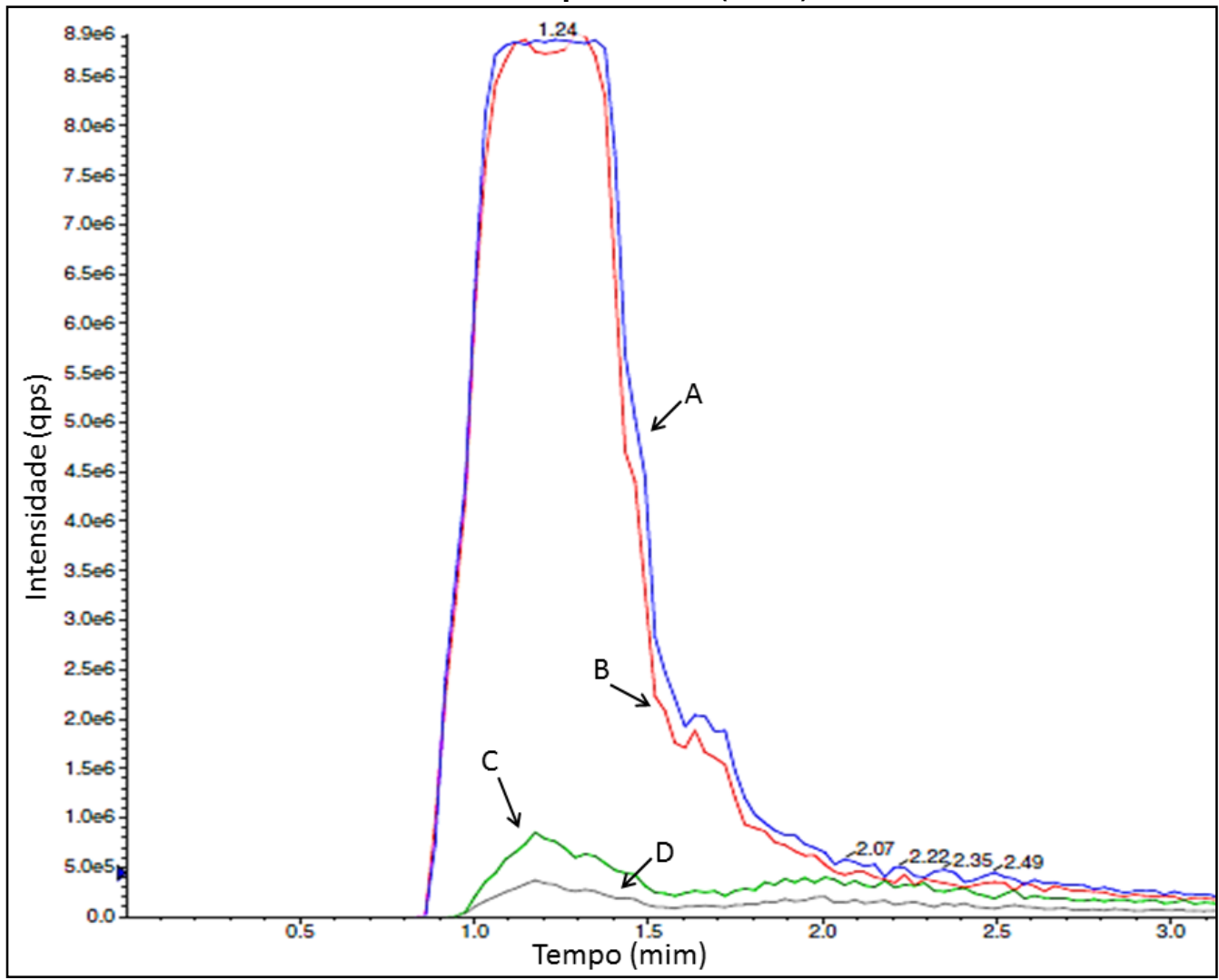

Fonte: Autores (2016)

Tabela 4 - Tamanho das massas dos compostos analisados e da massa das duas moléculas geradas a partir da fragmentação da massa original

\begin{tabular}{cccc}
\hline Composto & $\begin{array}{c}\text { Massa mãe } \\
\text { (Da) }\end{array}$ & $\begin{array}{c}\text { Massa (Da) } \\
\text { (fragmento 1) }\end{array}$ & $\begin{array}{c}\text { Massa (Da) } \\
\text { (fragmento 2) }\end{array}$ \\
\hline Carbofuran & 222.100 & 165.200 & 123.100 \\
Quinclorac & 242.000 & 224.100 & 161.100 \\
\hline
\end{tabular}

Fonte: Autores (2016)

Considerando cada ponto de coleta, nota-se que o P1 foi o ponto que apresentou mais amostras com valores detectáveis e quantificáveis, sendo $33,33 \%$ delas quantificáveis para carbofuran e 8,33\% quantificáveis para quinclorac. O P2 também apresentou amostras com concentrações de agrotóxico detectáveis e quantificáveis, no entanto, em apenas $25 \%$ do total de amostras deste ponto foi possível quantificar o agrotóxico carbofuran. O quinclorac não esteve presente nas amostras do P2. Já no 
REA - Revista de estudos ambientais (Online)

v.18, n. 1, p.30-45, jan./jun. 2016

P3, 6 amostras apresentaram alguma concentração de agrotóxico, todas para carbofuran, porém apenas em 2 amostras $(8,33 \%)$ foi possível quantificar a concentração do carbofuran. E, por fim, o P4 apresentou amostras com valores detectáveis apenas para 0 agrotóxico carbofuran (Tabela 5).

Tabela 5 - Data das coletas relacionadas com o período da safra, os meses que em que foram encontrados valores detectáveis $(<L O Q)$ e a média dos valores quantificáveis encontrados nas duas alíquotas analisadas por ponto em cada mês, todos separados por agrotóxico verificado.

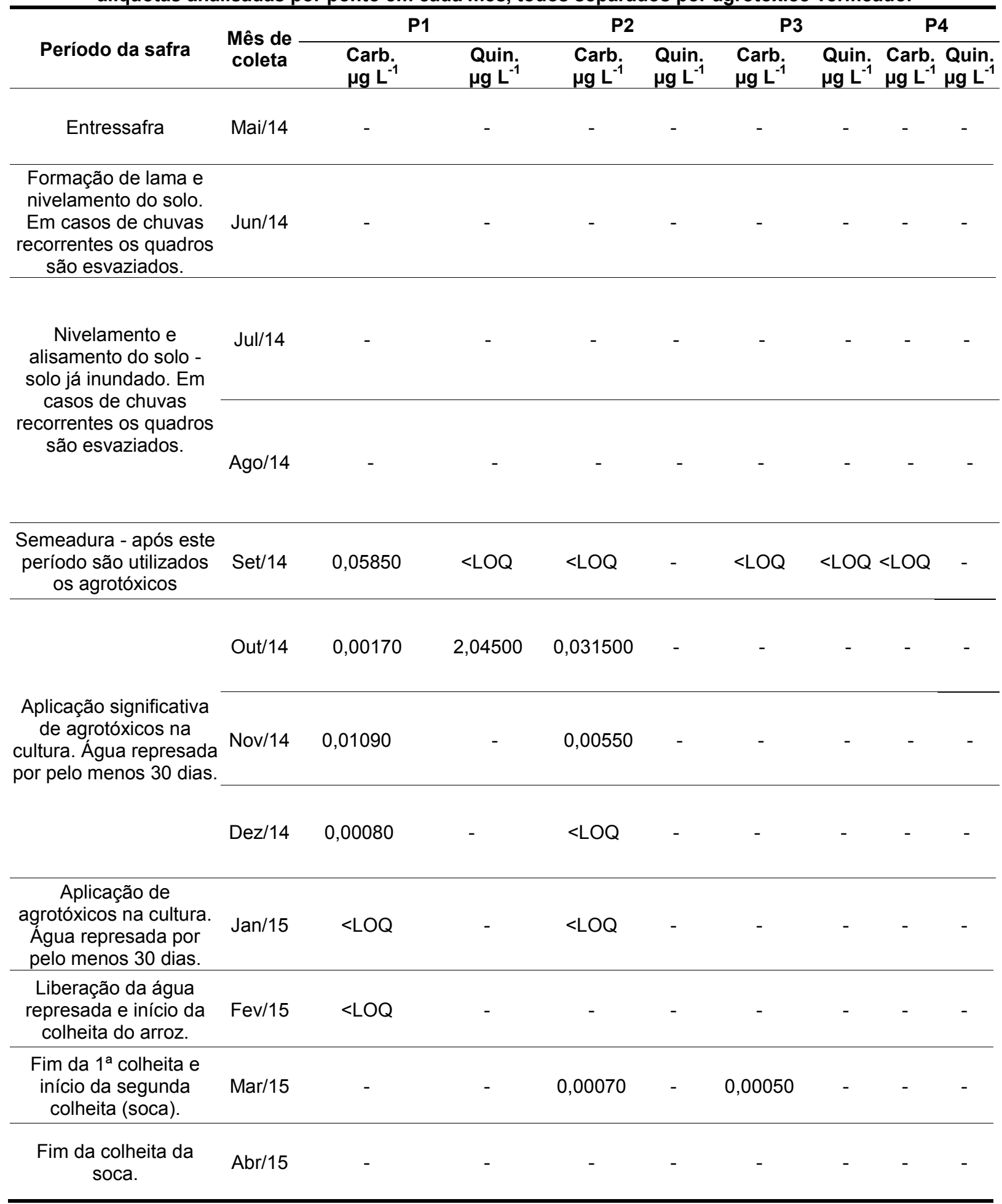


REA - Revista de estudos ambientais (Online) v.18, n. 1, p.30-45, jan./jun. 2016

Estes fatos são consequência do uso de terra para fins agrícolas na cidade de Camboriú, como é possível ver na Figura 4, onde o maior uso agrícola fica concentrado nos arredores dos pontos 1 e 2. Já o P3, apesar de receber toda a água que passa nos pontos 1 e 2, fica distante deles, o que permite que os agrotóxicos iniciem seu processo de degradação além de poderem ficar retidos no sedimento, na superfície das plantas e serem lixiviados durante 0 percurso, principalmente $O$ pesticida quinclorac (COSTA; SANT'ANA, 2008) que possui um tempo de meia vida em água de 14,7 dias (SILVA, 2011), muito inferior ao apresentado pelo agrotóxico carbofuran, o qual apresenta um tempo de meia vida em água de aproximadamente 40 dias (SANTIAGO-MOREIRA, 2013).

A persistência em água destes dois compostos também se diferencia. $\mathrm{O}$ agroquímico quinclorac mostra uma persistência em água de até 84 dias (SILVA, 2011) enquanto o carbofuran apresenta uma persistência em água de até 56 dias (CAMARGO, 2010). Estes dois agrotóxicos, quando comparados com outros químicos utilizados na rizicultura, como o Clomazone, Fipronil e Beta-Ciflutrina, também apresentam uma persistência em água maior (GRÜTZMACHER et al., 2008).

O ponto de coleta número 4 apresentou apenas valores detectáveis do pesticida carbofuran, $o$ que pode ser explicado pelo fato de que basicamente toda a agricultura cultivada naquela região é de hortaliças, e não de arroz irrigado, como nos pontos 1 e 2 . O cultivo de hortaliças utiliza, dentre outros, o agrotóxico carbofuran (SOUSA, 2016), este agrotóxico é utilizado também em inúmeras culturas e até para fins domésticos e industriais (HIRATA et al., 2003), já o agrotóxico quinclorac tem uso quase exclusivo para o cultivo do arroz irrigado (CONCENCCO, 2008). Por isso podese encontrar traços de carbofuran na amostra do $\mathrm{P} 4$, mas não foi possível encontrar traços de quinclorac.

Figura 4 - Mapa de uso e ocupação de terras da cidade de Camboriú do ano de 2010 com destaque para os pontos de coleta utilizados no presente estudo

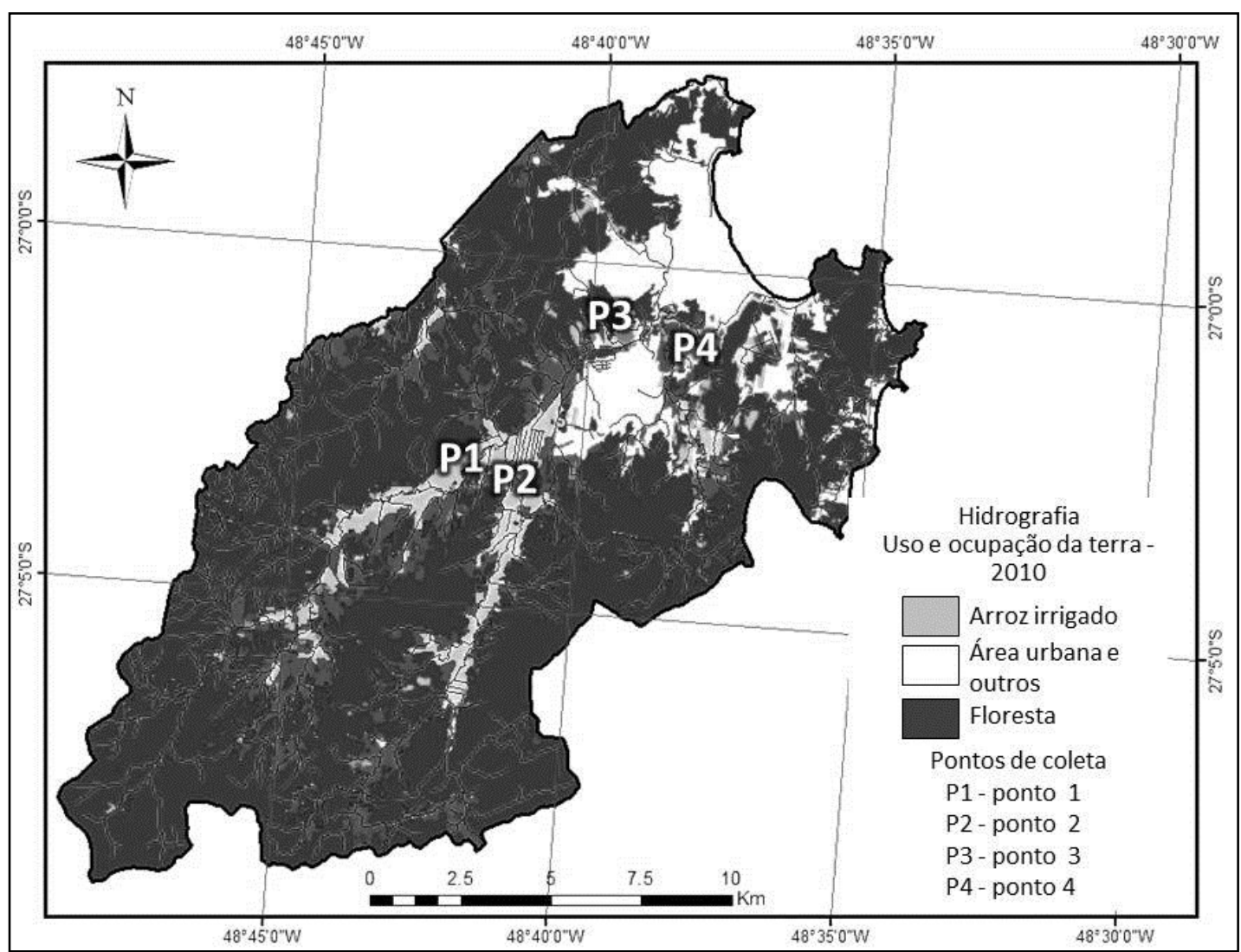

Fonte: Adaptado de EPAGRI/CIRAM (2015)

A biodisponibilidade e degradação microbiana, que dependem diretamente de diversas propriedades do solo como o conteúdo da matéria orgânica, tipo de solo e 


\section{REA - Revista de estudos ambientais (Online) v.18, n. 1, p.30-45, jan./jun. 2016}

tamanho das partículas, são fatores que podem interferir no número de vezes em que os agrotóxicos analisados foram encontrados (SANTIAGO-MOREIRA, 2013).

Uma das hipóteses para justificar o motivo pelo qual o agrotóxico carbofuran foi encontrado em maior número de vezes, deve-se ao fato de que basicamente todas as culturas praticadas na cidade de Camboriú, sejam elas de arroz irrigado ou hortaliças, localizam-se muito próximas as margens dos rios e basicamente todas possuem saída direta da água utilizada na irrigação para o rio. Além disso, o carbofuran tem solubilidade muito maior do que o quinclorac (SILVA, 2011) e possui característica apolar (LEÃO, 1997), que facilita sua hidrólise em meio básico pela presença da função éster em sua molécula (HIRATA et al., 2003), assim sua detecção em meio aquoso é facilitada (NUNES, 2002).

$\mathrm{O} \mathrm{pH}$ do meio também interfere na meia-vida do composto, uma vez que a sua taxa de hidrólise aumenta junto com o aumento do $\mathrm{pH}$ do meio onde se encontra, podendo manter o composto por mais tempo neste meio (EVERT, 2015). No geral, o comportamento dos carbamatos em água é importante, pois a reação de hidrólise diminui a ação do inseticida sob a planta cultivada, o que leva a um aumento no volume do produto aplicado, aumentando também as chances de contaminação dos recursos ambientais pela formação dos seus produtos de degradação que atingem não só as águas como também os alimentos gerados no campo (CALDAS, 2009).

O herbicida quinclorac, apesar de ter um tempo de meia-vida muito curto, apresenta uma elevada persistência em água, a qual é decorrente de sua baixa solubilidade (SILVA, 2011). A inexistência deste pesticida nas amostras analisadas pode ser um reflexo da redução da sua utilização por parte dos produtores de arroz irrigado durante o período de amostragem. Resultados estes semelhantes aos encontrados em um estudo realizado com amostras coletadas nos rios Vacacaí e Vacacaí-Mirim, na safra de 2003/4, que também apontou como hipótese para a diminuição da presença do herbicida a redução da utilização do quinclorac nas lavouras (MARCHESAN, 2010).

O coeficiente de partição octanoágua (Kow) é também um parâmetro importante na análise de moléculas orgânicas no ambiente, já que aponta a tendência que o químico tem de se particionar com a fase aquosa ou com a fase orgânica (LEÃO, 1997). Neste quesito, o quinclorac apresenta um Kow significativamente menor do que o carbofuran. Isto confere ao quinclorac a característica hidrofílica (SILVA, 2011), aumentando sua meia vida em água e podendo fazer com que, mesmo que aplicado em pequenas quantidades, seja detectado pela metodologia empregada.

O volume encontrado para o composto quinclorac no mês de outubro de 2014 foi muito superior aos volumes encontrados para o pesticida carbofuran durante $\mathrm{o}$ estudo. Um monitoramento realizado em Rio Grande do Sul, nos rios Vacacaí e Vacacaí-mirim entre os anos de 2003 e 2007 determinou um padrão semelhante para volume de agrotóxicos quinclorac e carbofuran encontrados nas amostras. No trabalho foi registrado volumes mais altos para carbofuran e menores para o quinclorac, sendo eles $0,25 \mathrm{\mu g} \mathrm{L}^{-1}$ para quinclorac e $0,06 \mu \mathrm{g} \mathrm{L}^{-1}$ para carbofuran (MARCHESAN, 2010). Outros estudos em bacias hidrográficas importantes do estado de Santa Catarina mostraram mesmo modelo de ocorrência para os agrotóxicos analisados (VIEIRA, 2016).

Este padrão se repete frequentemente, como mostra um trabalho realizado em Santa Catarina onde no município de Pouso Redondo a concentração máxima encontrada para carbofuran foi de $8,3 \mu \mathrm{g} \mathrm{L}^{-1}$, sendo inferior à concentração do quinclorac na cidade de Taió (SC) que foi extremamente alta, de 20,2 $\mu \mathrm{g} \mathrm{L}^{-1}$ (DESCHAMPS, 2013), apresentando riscos ecológicos (RESGALLA JR., 2007).

Tratando-se de águas superficiais ou água potável - para consumo humano -, não existe no Brasil uma legislação vigente que regulamenta o Valor Máximo Permitido (VMP) do pesticida quinclorac (CALDAS et al., 2011). Mas, no geral, a resolução 357 (CONAMA, 2005) estabelece valores máximos permitidos menores do que o Ministério da Saúde. Para o agrotóxico carbofuran, o Ministério da saúde contempla um valor máximo permitido de $7 \mu \mathrm{g} \cdot \mathrm{L}^{-1}$ (BRASIL 2011). O VMP também é aludido por outras entidades para o mesmo agrotóxico. A Tabela 6 apresenta os VMPs para os agrotóxicos testados, sugeridos por algumas entidades nacionais e internacionais e compara com os valores aqui encontrados. 


\section{REA - Revista de estudos ambientais (Online) v.18, n. 1, p.30-45, jan./jun. 2016}

Tabela 6 - Valores máximos permitidos (VMP) em água superficial dos agrotóxicos quinclorac e valor máximo encontrado nas amostras analisadas.

\begin{tabular}{lcccccc}
\hline $\begin{array}{c}\text { Agrotóxico } \\
\text { analisado }\end{array}$ & $\begin{array}{c}\text { VMP } \\
\text { segundo } \\
\text { Ministério } \\
\text { Saúde } \\
\left(\mu \mathrm{g} \mathrm{L}^{-1}\right)\end{array}$ & $\begin{array}{c}\text { VMP } \\
\text { segundo } \\
\text { EMBRAPA } \\
\left(\mu \mathrm{g} \mathrm{L}^{-1}\right)\end{array}$ & $\begin{array}{c}\text { VMP } \\
\text { segundo } \\
\text { OMS } \\
\left(\mu \mathrm{g} \mathrm{L}^{-1}\right)\end{array}$ & $\begin{array}{c}\text { VMP } \\
\text { segundo } \\
\text { EEC para 1 } \\
\text { agrotóxico } \\
\left(\mu \mathrm{g} \mathrm{L}^{-1}\right)\end{array}$ & $\begin{array}{c}\text { VMP segundo } \\
\text { EEC para } \\
\text { todos os } \\
\text { agrotóxicos } \\
\left(\mu \mathrm{g} \mathrm{L}^{-1}\right)\end{array}$ & $\begin{array}{c}\text { Valores } \\
\text { máximos } \\
\text { encontrados } \\
\text { nas amostras } \\
\left(\mu \mathrm{g} \mathrm{L}^{-1}\right)\end{array}$ \\
\hline Quinclorac & - & - & - & 0,01 & 0,05 & 2,04500 \\
Carbofuran & 7 & 4 & 0,7 & 0,01 & 0,05 & 0,05850 \\
\hline
\end{tabular}

Fonte: BRASIL (2011), EMBRAPA (2015), WHO (2003), EEC (1980)

Considerando a regulamentação do Ministério da Saúde e as sugestões da EMBRAPA (2015) e da OMS para o valor máximo permitido para o agrotóxico carbofuran, observa-se que nenhuma amostra coletada durante o período de estudo apresentou valor maior do que o permitido. Contudo, se for levado em consideração os valores propostos pela
EEC, nota-se que o agrotóxico carbofuran ultrapassou o valor máximo permitido para cada agrotóxico individualmente no ponto 1 de coleta nos meses de setembro e novembro de 2014 e no ponto 2 no mês de outubro (Tabela 6). A Figura 5 mostra a variação da concentração em valores quantificáveis do agrotóxico carbofuran durante o monitoramento.

Figura 5 - Variação da concentração do agrotóxico carbofuran ( $\mu \mathrm{g} \mathrm{L}^{-1}$ ) durante o período de estudo, analisado por ponto de coleta

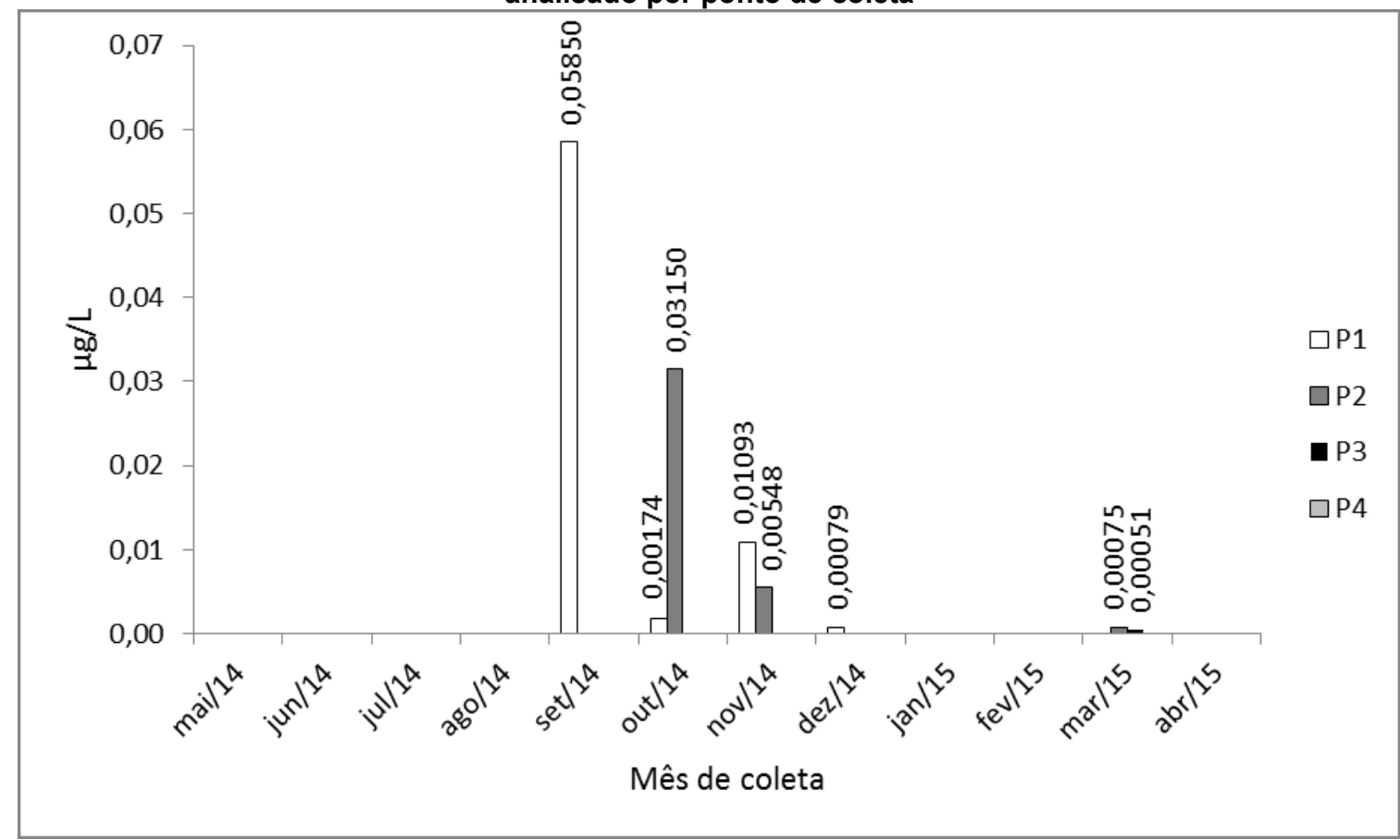

Fonte: Autores (2016)

No Brasil não há legislação vigente que sugere valor máximo permitido para o agrotóxico quinclorac em água potável. No entanto, pelas exigências da EEC também se pode considerar que no mês de outubro de 2014 as amostras coletadas no ponto 1 apresentaram um valor maior do que o recomendado de 2,045 $\mu . \mathrm{L}^{-1}$. Neste mês a concentração do agrotóxico quinclorac foi superior ao valor máximo permitido para a soma total de agrotóxicos (Tabela 6).

A primeira presença constatada dos agrotóxicos foi no mês de setembro de 2014 , o que mostra que esta utilização foi de forma 


\title{
REA - Revista de estudos ambientais (Online)
} v.18, n. 1, p.30-45, jan./jun. 2016

correta, considerando que o período de aporte de agrotóxicos se dá depois da preparação do solo (meses de julho e agosto) e há um manejo intenso dos quadros em outubro e novembro. A bula dos agrotóxicos e as indicações da ANVISA pedem que o carbofuran seja utilizado após a inundação dos quadros (FMC, 2015) e o quinclorac seja utilizado após emergência (que se dá logo após a semeadura), tendo os dois, possibilidade de uma nova utilização em casos de reaparecimento das pragas alvo (PORTAL ANVISA, 2015).

Contudo, apesar de haver esforços por parte de entidades locais e boa vontade dos agricultores, a utilização incorreta dos pesticidas e a manutenção errada da lavoura e dos materiais utilizados para a distribuição dos agrotóxicos nos terrenos também podem acontecer. Em algumas cidades há um aumento da turbidez das águas dos rios situados nas proximidades das lavouras durante o período de preparação do solo, causados pelo esvaziamento dos quadros de arroz depois da formação do lodo, contrariando assim as normas técnicas, e liberando assim altas cargas de agrotóxicos no meio (CADORIN,2011).

\section{Conclusão}

A bacia hidrográfica do rio Camboriú é influenciada pela rizicultura praticada no município de Camboriú. Este tipo de atividade pode ter consequências graves sob o meio ambiente, por isso, monitoramentos de agrotóxicos utilizados em sistemas convencionais de produção agrícola em rios são importantes instrumentos de controle $e$ proteção ambiental e da saúde. A metodologia de coleta e a extração em fase sólida, bem como o emprego da cromatografia líquida acoplada a espectrometria de massa tandem foram eficientes para a identificação, detecção e quantificação dos agrotóxicos quinclorac e carbofuran, uma vez que conseguiu-se encontrar valores muito baixos dos químicos analisados nas amostras coletadas. As concentrações achadas para o agrotóxico carbofuran não ultrapassaram os valores recomendados pelo Ministério da Saúde, EMBRAPA e OMS. Estas entidades não sugerem valores máximos permitidos para o agrotóxico quinclorac. Contudo, considerando os valores máximos permitidos pela CEE individualmente para cada agrotóxico, o carbofuran apresentou valores acima dos recomendados nos meses de setembro $\left(0,05850 \mu \mathrm{g} \mathrm{L}^{-1}\right)$ e novembro $\left(0,01090 \mu \mathrm{g} \mathrm{L}^{-1}\right)$ de 2014 nas amostras do P1 e no mês de outubro de 2014 nas amostras do P2 $\left(0,03150 \mu \mathrm{g} \mathrm{L}^{-1}\right)$. A CEE também estipula valores máximos para a soma de agrotóxicos encontrados e, considerando-se estes valores, o agrotóxico carbofuran se mostrou superior apenas no mês de setembro de 2014 nas amostras do P1 $\left(0,05850 \mu \mathrm{g} \mathrm{L}^{-1}\right)$. Já o agrotóxico quinclorac apresentou valores superiores aos máximos permitidos pela CEE para a soma de agrotóxicos no mês de outubro de 2014 $\left(2,04500 \mu \mathrm{g} \mathrm{L}^{-1}\right)$.

5 Monitoring the Quinclorac and Carbofuran Pesticides in the Camboriú River, municipality of Camboriú, Santa Catarina State

\begin{abstract}
In Brazil, one of the largest irrigated rice producers is the state of Santa Catarina, where the watershed of the Camboriu river is located. The use of agrochemicals in the rhiziculture confers to this practice a great potential of water pollution, highlighting the pesticides quinclorac and carbofuran, which are used in large scale in this crop. During twelve months (May 2014 to April 2015) four locals in the basin were visited and 48 water samples were collected (1 collection/ point / month). These water samples were prepared by extraction in solid phase and analyzed in liquid chromatograph coupled to tandem mass spectrometer. The results showed that quinclorac was found only in the water samples collected near the rice crop places, whereas carbofuran was found in other points as well. All contaminated samples were found during the crop period. Furthermore, quinclorac was present in detectable and quantifiable values in a smaller number of water samples than the carbofuran pesticide. However, carbofuran was not present in higher concentrations than the maximum values allowed suggested by EMBRAPA and by Health Ministry. For quinclorac there are no recommended limit values.
\end{abstract}

Keywords: Irrigated rice crop. Mass spectrometry. Residues. Surface water. 
REA - Revista de estudos ambientais (Online) v.18, n. 1, p.30-45, jan./jun. 2016

\section{Referências}

AGEITEC. Riscos de contaminação. Disponível em:

$<$ http://www.agencia.cnptia.embrapa.br/gestor/agri cultura_e_meio_ambiente/arvore/CONTAG01_42 _210200792814.html>. Acesso em: 18 nov. 2015.

ANVISA. Índice monográfico - Quinclorac. Disponível em: $<$ http://portal.anvisa.gov.br/wps/wcm/connect/61e 0d400474597379f6fdf3fbc4c6735/q04.pdf?MOD= AJPERES $>$. Acesso em: 18 nov. 2015.

BIANCHIN, H. W.; WATANABE M.; YAMAGUCHI C. K.; VIRTUOSO J. C. A gestão da água no cultivo do arroz: um estudo de caso no município de Turvo - SC. Disponível em: $<\mathrm{http}: / / w w w . a p e c . u n e s c . n e t / / X \_E E C /$ sessoes_tem aticas/\%C3\%81rea\%20tem $\%$ C3\%A1tica $\% 201 \% 2$ 0 -

\%20Desenvolvimento\%20socioambiental/3\%20G EST\%C3\%830\%20DA\%20\%C3\%81GUA.pdf>. Acesso em: 18 nov. 2015.

BRASIL. Ministério da saúde. Dispõe sobre os procedimentos de controle e de vigilância da qualidade da água para consumo humano e seu padrão de potabilidade. Portaria n. 2.914, de 12 de dezembro de 2011.

CADORIN, C. B. Procedimentos de perícia ambiental aplicados na atividade da rizicultura: avaliação de impactos ambientais causados pelo uso de defensivos agrícolas na região sul do estado de Santa Catarina, Criciúma, agosto de 2011.

CALDAS, S. S.; GONÇALVES F. F.; PRIMEL E. G.; PRESTES O. D.; MARTINS M. L.; ZANELLA $R$. Principais técnicas de preparo de amostra para a determinação de resíduos de agrotóxicos em água por cromatografia líquida com detecção por arranjo de diodos e por espectrometria de massas. Química Nova. v. 34, n. 9, p. 1604-1617. 2011.

CALDAS, S. S. Otimização e validação de métodos empregando DLLME, SPE, HPLCDAD e LC-ESI-MS-MS para determinação de agrotóxicos em água subterrânea. 2009. $125 \mathrm{f}$. Dissertação (Programa de pós-graduação em química) - Universidade Federal do Rio Grande do Sul, Rio Grande do Sul. 2009.

CAMARGO, B. V. Macroinvertebrados da lavoura de arroz irrigado tratada com os agrotóxicos carbofuran e penoxsulan. 2010. 47 f. Dissertação (Mestrado em Biodiversidade Animal) - Centro de Ciências Naturais e Exatas, Universidade Federal de Santa Maria. Santa Maria, Rio Grande do Sul. 2010.

CAMBORIÚ. Prefeitura de Camboriú. História. Disponível
$<$ http://www.cidadedecamboriu.sc.gov.br/estudant e.php>. Acesso em: 18 nov. 2015.

CEE. Directive 80/778/EEC relating to the quality of water intented for human consumption. Official Journal of European Communities, n. L 299, 1980.

CHIARADIA, M. C. Desenvolvimento, validação e aplicação de métodos para análise multirresidual de agrotóxicos em suco de laranja e tangerina utilizando CLAE-DAD, CLEM-EM e CLUE-DAD. 2009. 119 f. Tese (Doutorado em Química) - Departamento de Química Analítica, Universidade Estadual de Campinas, Campinas. 2009.

COMITÊ CAMBORIÚ. Comitê de Gerenciamento da Bacia Hidrográfica do Rio Camboriú. Bacia Hidrográfica. Disponível em: $<$ http://www.comitecamboriu.com.br/baciahidrografica/>. Acesso em: 18 nov. 2015.

CONAMA - CONSELHO NACIONAL DO MEIO AMBIENTE. Dispõe sobre a classificação dos corpos de água e diretrizes ambientais para o seu enquadramento, bem como estabelece as condições e padrões de lançamento de efluentes, e dá outras providências. Resolução n. 357 de 17 de março de 2005. Alterada pela Resolução $410 / 2009$ e pela 430/2011. Publicada no DOU n. 053, de 18 de mar. 2005, p. 58-63.

CONCENÇO, G.; MELO. P. T. B. S.; ANDRES A.; FERREIRA E. A.; GALON L.; FERREIRA F. A.; SILVA A. A. Método rápido para detecção de capim-arroz (Echinochloa spp.) ao quinclorac. Planta Daninha, Viçosa, MG, v. 26, n. 2, p. 429437, 2008.

COSTA, L. L. F. Desenvolvimento de métodos analíticos baseados em SPME para a determinação de herbicidas (alaclor, atrazina, propanil e pendimetalina) em aguas superficiais. 2007. 123 p. Tese (Doutorado em Ciências dos Alimentos) - Departamento de ciência e tecnologia de alimentos, Universidade Federal de Santa Catarina, Florianópolis. 2007.

COSTA, L. L. F., SANT'ANA E. S. Determinação de herbicidas usados no cultivo de arroz irrigado na região sul do estado de Santa Catarina através da SPME-GC-ECD. Química Nova. v. 31, n. 1, 79-83. 2008.

DEMOLINER, A.; CALDAS S. S.; COSTA F. P.; GONÇALVES F. F.; CLEMENTIN R. M.; MILANI M. R.; PRIMEL E. G. Development and validation of a method using SPE and LC-ESI-MS-MS for the determination of multiple classes of pesticides and metabolites in water samples. Journal of the brazilian chemical society v. 21, n. 8. 2010.

DESCHAMPS, F. C.; NOLDIN J. A.; MARSCHALEK R.; EBERHARDT D. S.; KLEVESTON R. Agrotóxicos na água superficial sugerem melhorias nas práticas de manejo das 


\section{REA - Revista de estudos ambientais (Online) v.18, n. 1, p.30-45, jan./jun. 2016}

lavouras de arroz irrigado em Santa Catarina. In: CONGRESSO BRASILEIRO DE ARROZ IRRIGADO, 8., 2013, Santa Maria, RS. Anais... Santa Maria, RS: UFSM; Sosbai, 2013. p. 892895.

EMBRAPA. Cultivo do arroz irrigado no Brasil. Disponível em: $<$ https://sistemasdeproducao.cnptia.embrapa.br/F ontesHTML/Arroz/Arroz/rrigadoBrasil/cap13.htm>. Acesso em: 18 nov. 2015.

EPAGRI. Tabelas de produção. Disponível em: $<$ http://www.epagri.sc.gov.br/?page_id=2623>. Acesso em 18 nov. 2015.

EPAGRI/CEPA. Síntese Anual da Agricultura de Santa Catarina - 2012-2013. 2013. 177 f. Centro de Socioeconomia e Planejamento Agrícola Epagri/Cepa. Florianópolis, Santa Catarina.

EPAGRI/CIRAM. Mapas. Disponível em: $<$ http://ciram.epagri.sc.gov.br/index.php?option=co m_content\&view=article\&id=1907\&ltemid=691 $>$. Acesso em: 18 nov. 2015

EPAGRI/CIRAM. Rede de monitoramento hidrometeorológico para a Bacia Hidrográfica do Rio Camboriú - SC. 2011. 12 f. Florianópolis.

EVERT, S. Environmental fate of Carbofuran. Environmental Monitoring Branch. Sacramento: Department of Pesticide Regulation. Disponível em:

$<$ http://www.cdpr.ca.gov/docs/emon/pubs/fateme mo/carbofuran.pdf>. Acesso em: 23 abr. 2015.

FARIA, L. J. da S. Avaliação de diferentes sorventes na extração e fase sólida de pesticidas em água. Desenvolvimento e validação de metodologia. 2004. $61 \mathrm{f}$. Dissertação (Programa de pós-graduação em química analítica) - Universidade Estadual de Campinas, São Paulo, 2004.

FMC. Relatório do produto: Furadan 100gr. Disponível em: $<$ https://www.fmcagricola.com.br/bula_geraPDF.a spx?cod=3 $>$. Acesso em: 18 nov. 2015.

GRÜTZMACHER, D. D.; GRUTZMACHER A. D.; AGOSTINETTO D.; LOECK A. E.; ROMAN R.; PEIXOTO S. C.; ZANELLA R. Monitoramento de agrotóxicos em dois mananciais hídricos no sul do Brasil. Revista Brasileira de Engenharia Agrícola e Ambiental. Campina Grande, PB. v. 12 , n. 6, p. 632-637. 2008.

HIRATA, R.; SKORTZARU B.; NARCISO E. S. Avaliação da degradação de inseticidas, em função do $\mathrm{pH}$, utilizando Drosophila melanogaster e teste de inibição enzimática. Arquivos do Instituto Biológico. São Paulo, v. 70, n. 3, p. 359-365. 2003.
IBGE. Levantamento Sistemático da Produção Agrícola. Disponível em: $<$ http://www.ibge.gov.br/home/estatistica/indicador es/agropecuaria/lspa/defaulttab.shtm $>$. Acesso em: 18 nov. 2015.

IBGE. Santa Catarina "Camboriú " produção agrícola municipal - cereais, leguminosas e oleaginosas - 2007. Disponível em: $<$ http://cidades.ibge.gov.br/xtras/temas.php?codm un=420320\&idtema=18>. Acesso em 15 set. 2016.

KRUZ, M. H. S. Estudo de métodos empregando extração em fase sólida e análise por HPLC-DAD e GC-ECD para a determinação de resíduos de pesticidas em águas e da degradação a campo. 2007. 163 f. Tese (Doutorado em Química) - Centro de Ciências Naturais e Exatas, Universidade Federal de Santa Maria. Santa Maria, Rio Grande do Sul. 2007.

LEÃO, J. C. Estudo do movimento do Carbofuran no perfil de um solo agrícola. 1997. $96 \mathrm{f}$. Dissertação (Mestrado em Engenharia Ambiental). Departamento de Tecnologias de Saneamento Ambiental, Universidade Federal de Santa Catarina. Florianópois. 1997.

MARCHESAN, E.; SARTORII G. M. S.; AVILAI L. A. DE; MACHADOII S. L. DE O.; ZANELLA R.; PRIMEL E. G.; MACEDO V. R. M.; MARCHEZANI M. G. Resíduos de agrotóxicos na água de rios da Depressão Central do Estado do Rio Grande do Sul, Brasil. Ciência Rural. Santa Maria, RS. v. 40, n. 5, p. 1053-1059. 2010.

NUNES, G. S.; SANTOS T. C. R.; BARCELÓ D.; PIMENTA A. S.; RIBEIRO M. L. Extração por fluido supercrítico de alguns inseticidas carbamatos em amostras de batata, com determinação por HPLC/fluorescência e confirmação por HPLC/espectrometria de massas. Química Nova. v. 25, n. 2, p. 214-220. 2002.

PEREIRA, M. B. Avaliação da técnica por extração por SPE e GC-(EI)-MS/MS na análise de agrotóxicos em água de lavoura de arroz irrigado. 2012. 103 f. Dissertação (Mestrado em Química) - Centro de Ciências Naturais e Exatas, Universidade Federal de Santa Maria. Santa Maria, RS. 2012

PORTAL ANVISA. Índice monográfico carbofurano. Disponível em: $<$ http://portal.anvisa.gov.br/wps/wcm/connect/778 da6004745759c839bd73fbc4c6735/C06++Carbof urano.pdf?MOD=AJPERES $>$. Acesso em: 18 nov. 2015.

PRIMEL, E. G.; ZANELLA R.; KURZ M. H. S.; GONÇALVES F. F.; MACHADO S. de O.; MARCHEZAN E. Poluição das águas por herbicidas utilizados no cultivo do arroz irrigado na região central do estado do Rio Grande do Sul, 


\section{REA - Revista de estudos ambientais (Online) v.18, n. 1, p.30-45, jan./jun. 2016}

Brasil: predição teórica e monitoramento. Química Nova. v. 28, n. 4, p. 605-609, 2005.

REIMCHE, G. B. Impacto de agroquímicos usados na lavoura de arroz irrigado sobre a qualidade da água de irrigação e na comunidade zooplantônica. 2010. 115 f. Dissertação (Mestrado em Agronomia) - Centro de Ciências Rurais, Universidade Federal de Santa Maria. Santa Marias, RS. 2010

RESGALLA JR, C.; NOLDIN J. A,; TAMANAHA M. S.; DESCHAMPS F. C.; EBERHARDT D. S.; RÖRIG L. R. Risk analysis of herbicide quinclorac residues in irrigated rice areas, Santa Catarina, Brazil. Ecotoxicology. v. 16. p. 565-571. 2007.

RIBANI, M.; BOTTOLI C. B. G.; COLLINS C H.; JARDIM I. C. F. S.; MELO L. F. C. Validação em métodos cromatográficos e eletroforéticos. Química Nova. v. 27, n. 5, p. 771-780. 2004

RIZZARDI, M.A.; VIDAL R. A.; FLECK N. G.; AGOSTINETTO D. Resistência de plantas aos herbicidas inibidores da acetolactato sintase. Planta Daninha, Viçosa, MG, v.20, n.1, p.149158, 2002.

RUELA, A. L. M.; ARAÚJO M. B.; PEREIRA G. R. Desenvolvimento e validação de um método analítico rápido por cromatografia líquida de alta eficiência para determinação de nimesulida em estudos de liberação in vitro. Química Nova. v. 32, n. 1, p. 165-168. 2009.

SANTIAGO-MOREIRA, M. R.; MUCCI J. L. N.; CISCATO C. H. P.; MONTEIRO S. H.; ABAKERLI R. B. Estudo do inseticida carbofurano em solo e sedimento de área de produção de arroz irrigado e controle do gorgulho aquático oryzophagus oryzae, Taubaté, São Paulo, Brasil. Arquivos do Instituto Biológico. São Paulo. v. 80 , n. 1, p. 125-128. 2013.

SILVA, D. R. O. da.; AVILA L. A. de; AGOSTINETTO D.; MAGRO T. D.; OLIVEIRA E. de; ZANELLA R.; NOLDIN J. A. Monitoramento de agrotóxicos em águas superficiais de regiões orizícolas do sul do Brasil. Ciência Rural. Santa Maria. v. 39, n. 9, p. 2383-2389. 2009.

SILVA, D. R. O. da.; ÁVILA L. A. de; AGOSTINETTO D.; BUNDTA. D. C. Ocorrência de agrotóxicos em águas subterrâneas de áreas adjacentes a lavouras de arroz irrigado. Química Nova v. 34, n. 5, p. 748-752, 2011.
SKOOG, D. A.; WEST, D. M.; HOLLER, F. J.; $\mathrm{CROUCH}$, S. R. Cromatografia Líquida de Alta Eficiência. In: DOUGLAS A. SKOOG. Fundamentos de Química Analítica. São Paulo: Thomson, 2006. p. 954-945.

SOUSA, E. S. Desenvolvimento e validação de uma metodologia analítica para determinação de resíduos de agrotóxicos em hortaliças empregando cromatografia líquida com detector de arranjo de diodos. 2016. $101 \mathrm{f}$. Dissertação (Mestrado em Química). Departamento de Química, Universidade Federal da Paraíba. João Pessoa. 2016.

SOUZA, A. C. V. de. Pesquisa com arroz irrigado (oryza sativa l.) no sistema pré-germinado: melhoramento genético, toxidez por ferro e brusone, Florianópolis, 2012.

TREVISAN, M. J. Resíduo de carbofuran e de seus metabólitos carbofuran e 3-hidroxicarbofuran em frutos e folhas de laranjeira [Citrus sinensis (L.) Osbeck], determinados em cromatografia em fase gasosa. 2002. $91 \mathrm{f}$. Dissertação (Mestrado em Ciências) - Escola Superior de Agricultura Luiz de Queiroz. Piracicaba, São Paulo. 2002.

VIEIRA, D.C.; VIEIRA D. C.; NOLDIN J. A.; DESCHAMPS F. C.; RESGALLA C. Jr. Ecological risk analysis of pesticides used on irrigated rice crops in southern Brazil. Elsevier. 162. p. 42-54. 2016.

WHO. Carbofuran in drinking-water. Background document for preparation of WHO Guidelines for drinking-water quality. Geneva, World Health Organization (WHO/SDE/WSH/03.04/81). 2003.

WILLEMAN, N. F.; BACEGATO V. A.; FIGUEIREDO O. A. R. Legislação ambiental na produção de arroz irrigado da região do alto vale do Itajaí - SC. Geoambiente on-line. n. 8, p. 134148, 2007.

\section{Agradecimentos}

Ao Comitê de Gerenciamento da Bacia Hidrográfica do Rio Camboriú e ao Lions Clube de Balneário Camboriú pelo apoio financeiro, e ao Sindicato dos Trabalhadores Rurais de Camboriú pela colaboração durante as coletas. 